\section{CARMEN DE BURGOS, TRADUCTORA ${ }^{1}$}

\author{
María del Carmen Simón Palmer \\ (CSIC) Centro de Ciencias Humanas y Sociales \\ C/Albasanz, 26-28, 28037 Madrid \\ carmen.simon@cchs.csic.es
}

\begin{abstract}
In the first third of the $20^{\text {th }}$ century, Carmen de Burgos carried out an outstanding work to diffuse the knowledge of the foreign literature in Spain and translated more than thirty works of varied authors such as Ruskin, Renan, Moebius, Salgari or Rachilde. It has been chosen to arrange her translations according to the publishing houses that published them in order to show the different publishing or editorial lines of each publisher.
\end{abstract}

KEY WORDS: Carmen de Burgos; translation; Vda. Rodríguez Serra Publisher; Sempere Publisher; Maucci Publisher; Araluce Publisher.

Aunque resulte paradójico, dado el silencio en que durante siglos han permanecido la mayoría de las mujeres que escribieron en España, hubo al menos desde el siglo XVII algunas traductoras. La primera de que se tiene noticia es Isabel de Correa, poeta y traductora sefardí en 1693. Ya con la llustración, el contacto con otros paises, Francia especialmente, les lleva al conocimiento de idiomas, la mayoría de las veces de manera muy superficial como simple expresión de un nivel social, pero algunas van a traducir del francés como Rosario Romero a Mme de Graffigny.

En el siglo XIX, con la incorporación masiva de la mujer a la escritura, pasan de la treintena las que, junto a su obra de creación, realizan la labor de traductoras. Figuras de primer orden como Gertrudis Gómez de Avellaneda, que vierte al castellano del francés a Dumas padre, G. Lemoine o Victor Hugo; Fernan Caballero, a Madame Stael y Lammenais, Pardo Bazán, del alemán a Heine y del francés a $\mathrm{E}$. Goncourt; y Faustina Saez de Melgar, a Pierre Zaccone o F. Brener, Julia Asensi a Gautier, sirven de ejemplo. Algunos diarios como La Correspondencia de España, insertan en su parte inferior folletines de autores, franceses la mayoría, y así, García Balmaseda traduce diecisiete obras en diez años de Daudet, Dumas, Paul Feval, Feydeau, y versiona novelas de G. Sand y las policíacas de Emile Gaboriau. El resultado es que, como se ha demostrado, estas mujeres dieron a

\section{CARMEN DE BURGOS, TRANSLATOR}

RESUMEN: En el primer tercio del siglo XX, Carmen de Burgos realizó una notable tarea para lograr el conocimiento de la literatura extranjera en España y tradujo más de treinta obras de autores tan variados como Ruskin, Renan, Moebius, Salgari o Rachilde. Se ha elegido ordenar sus traducciones de acuerdo con las editoriales que las publicaron para distinguir la línea editorial de cada una de ellas.

PALABRAS CLAVE: Carmen de Burgos; Traducción; Editorial Vda. Rodríguez Serra; Editorial Sempere; Editorial Maucci; Editorial Araluce.

conocer las únicas versiones en español de algunas obras de escritores franceses (Botrel, 1987, 89-131).

Los vaivenes políticos de esos tiempos explican el conocimiento directo que algunas escritoras adquieren de otros idiomas, puesto que son llevadas al exilio por sus familiares o les acompañan en sus destinos profesionales. Este último es el caso de Sofía Casanova, que traduce directamente del polaco a Enrique Sienkiewicz, Bartek el vencedor y la famosa Quo Vadis?, y a Sofía Kowalewska del ruso; asimismo Emilia Gayangos, hija de Pascual de Gayangos, traducirá del alemán, o Angela Grassi, del italiano.

Con el cambio de siglo, los gobiernos liberales les brindarán ayudas oficiales, especialmente cuando se trata de maestras, para formarse en el extranjero y éste es el caso, al principio de su carrera, de Carmen de Burgos. Se ponen así al corriente de las modas literarias europeas, y aprovechando la ausencia de censura, en algunos casos vierten al castellano a autores prohibidos en otros países.

La proliferación de traducciones en los primeros años del siglo XX fue denunciada por Rivas Cherif (1920) en la revista España, donde comenta los abusos que algunos editores cometían a la hora de contratarlas y cómo esa situación repercutía en el sistema literario español: 
"Para asegurarse una ganancia con el menor riesgo posible, los editores se afanan por saturar el mercado de traducciones, cuya propiedad compran desde luego en un tanto alzado, reservándose de este modo el beneficio líquido de las restantes ediciones, que en las obras originales han de compartir con el autor, a quien siempre reserva la ley la propiedad intransferible de la edición en serie de sus obras completas. No a otra cosa se debe la actual invasión extranjera que padecemos" (Gallego, 2004, 482).

Como muy bien apunta Gallego, lo que ataca es la falta de rigor filológico en una multitud de traducciones, versiones 0 adaptaciones que no parecen aportar nada especial a la cultura española.

Entre las traductoras que al tiempo desempeñan tareas docentes, la más cercana a Carmen de Burgos es Magdalena de S. Fuentes, con la que mantiene relación profesional y se prologan mutuamente alguna obra.

Hemos elegido comentar las numerosas traducciones de Carmen de Burgos según las editoriales en que aparecieron porque puede apreciarse claramente la línea de cada una de ellas según los autores publicados En unos casos se busca el éxito comercial, asegurado por algún escándalo en el extranjero o por las numerosas ventas que preceden a la obra en el país de origen; en otros, como ocurre con la editorial Sempere, existe además una intención de dar a conocer la literatura europea en España a través de una cuidadosa selección de los principales autores contemporáneos.

\section{Carmen de Burgos, traductora en distintas EDITORIALES}

Sorprende que, en los ya numerosos libros dedicados a estudiar la obra de Carmen de Burgos, se ignoren las más de tres mil páginas que tradujo o versionó. Tan sólo Concha Núñez las ha comentado en algunos casos y estudiado especialmente a Leopardi.

¿Qué impulsó a nuestra autora a llevar a cabo este trabajo frenético? Creemos que en muchos casos se trató fundamentalmente de una cuestión de tipo económico, si bien es cierto que se aprecia una diferencia en el tipo de autores, según la editorial de que se trate, de manera que los de mayor calidad literaria aparecen en Sempere, con un director literario de prestigio como Blasco Ibáñez, sin que falten títulos que en muchos casos iban en contra de las ideas de la traductora, como se verá en los aparecidos en Maucci, por ejemplo. Con seis editoriales trabajará Carmen como traductora, y algunas veces de modo simultáneo.

\section{Editorial de la Vda. de Rodríguez Serra}

Es la primera en el tiempo la regentada por la Viuda de Rodríguez Serra, que se arriesga en unos momentos especialmente delicados para ella, algo que agradecerá y de lo que dejará constancia escrita Carmen de Burgos.

La, ya en 1904, viuda de Serra se inclina abiertamente hacia lo comercial, fuera de los compromisos adquiridos previamente por su esposo en vida. Como es frecuente en España, conocemos poco del funcionamiento interno del mundo editorial, y en este caso una de las escasas noticias nos la ofrece la revisión de una traducción del alemán, hecha unos meses antes por Ciro Bayo de $L a$ cuestión agraria de Kautsky, revisión exigida por el autor y que Pablo Iglesias aconseja a Bernardo Rodríguez Serra que haga Unamuno, en 1902. Pero don Bernardo fallece de apendicitis en diciembre de aquel año $y$, al parecer, su viuda comenzó la impresión sin atender el requerimiento del autor, lo que motiva una nueva carta de Pablo Iglesias a Unamuno, el 2 de marzo de 1903, porque "aunque no tengo motivo alguno para dudar de la mencionada señora" quiere estar seguro de que ha cumplido su palabra (Robles, 2005, 153-62). El mismo año en que aparece esta obra, 1904, Carmen de Burgos traduce dos libros para la editorial y es el primero el de Helen Keller, Historia de mi vida. Ella misma confiesa que escribió al Diario Universal sobre la conveniencia de traducir esta obra al castellano para que sirviera de ejemplo y estímulo en la enseñanza, pero fue la viuda de Rodríguez Serra la que recogió el guante y meses después le encargaba la traducción.

El texto de Helen Keller estaba directamente relacionado con su labor de profesora en la Escuela Normal y de Sordomudos y Ciegos. Elige a don Eloy Bejarano y Sánchez, Comisario regio del Colegio de Sordomudos y Ciegos para prologarla, el cual comienza por opinar sobre la traduc- 
tora que "tiene personalidad propia y bien ganada con su cotidiano y variadísimo trabajo" en varios diarios, y muchos libros que la acreditan como "escritora genial con un lugar preferente en la literatura patria", pero lamenta que no se conozca, en cambio, lo suficiente su labor como profesora numeraria de la Escuela Normal, y su competencia indiscutible en asuntos pedagógicos porque habia cursado "con verdadero aprovechamiento" sus cursos de Metodología especial pedagógica de los niños anormales, donde la conoció al ser el director de este establecimiento pedagógico.

Presupone que, como madre "amantísima", lamenta la escasa importancia que en España se da a los infelices ciegos y sordomudos y por eso ha emprendido la traducción de estas Memorias, "llamadas a producir verdadera sensación en el público", maravillado de que una joven por el sentido del tacto haya podido adquirir una ilustración tan extraordinaria. Pero Bejarano se muestra escéptico sobre el "altruismo" de los lectores para interesarse de veras por unos desventurados a los que no hacen caso ni sus familiares, y por eso agradece más el esfuerzo Carmen de Burgos y el sacrificio de la editora de la obra, "que sólo pueden prometerse el agradecimiento de las buenas almas y la tranquilidad que siempre queda después de ejecutar una obra de misericordia". Sin embargo, le queda la esperanza de que "su origen exótico, la fama de que le rodean los anuncios de prensa norteamericana y su conmovedor objeto" puedan estimular la curiosidad del público, que desee conocer a la heroína del libro, y a su eficiente institutriz y directora, miss Ana Nabsfield Sullivan, la cual ha logrado, según frases de su educanda, que ésta "vea con el alma y oiga con el corazón" haciéndola conocer "la oscuridad que ve y el silencio que escucha".

Respecto al contenido, el prologuista desconfía de la "admirable" corrección con que se expresa la joven. Recuerda que ni siquiera en España, donde nació fray Pedro Ponce de León, monje benedictino, inventor del arte de hacer hablar y escribir a los sordomudos, se ha llegado a tanto, aunque ha habido portentos como Martín de Martín y Ruiz, del que cuenta su biografía y lamenta su temprana muerte "por tuberculosis pulmonar, muy frecuente entre los sordomudos".

Tras el éxito de este primer ensayo, Carmen de Burgos continúa su colaboración con la Viuda de Serra y traduce la obra del conde Gera Mattachich, Loca por razón de Estado (Mattachich: 1904), prohibida y secuestrada en Austria. Se trataba de una historia de palpitante actualidad por lo que había sido impresa y publicada en dos días por la casa editorial (El Imparcial, 19-IX-1904, 3).

La princesa Maria Luisa de Sajonia, hija de Leopoldo II de Bélgica, casó con el principe Felipe de Sajonia-Coburgo en 1875 y tuvo con él dos hijos. En 1895 estableció una relación extramatrimonial con el Gera Mattachich, teniente del ejército austríaco, y se escapó con él. En 1898 el marido le retó y resultó herido, pero el amante pasó en la cárcel cuatro años acusado de falsificación, y a ella la encerraron en un psiquiátrico, de donde él la ayudó a huir. Finalmente el matrimonio se divorciaría en 1906.

La prensa española tomó partido sobre el comportamiento de los protagonistas, y Carmen tuvo que intervenir en el debate del diario El País, tachando a la sociedad de gazmoña e hipócrita. "El escritor no ha de pensar en los convencionalismos cuando ha de decir lo que siente, es preciso llegar a la verdad y al alma de los lectores". En su prólogo a las Memorias defiende que ha triunfado la ley del amor, que iguala a la realeza con los plebeyos y eso le ha valido la censura de un compañero de redacción, Baldomero Argente, del Diario Universal, de ideas quasi liberales. Cree que su artículo no es erudito sino "la opinión de un burgués, aspirante a una cartera, gordo, tranquilo", al que le parece su opinión una defensa del amor libre. Carmen recuerda su sonrisa al leer que la princesa tenía ya 47 años y no era bella, y le pregunta si las mujeres no pueden amar cuando pasan de cierta edad y la solución está en encerrarlas en un manicomio, cuando su esposo le había confesado, además, su amor por su suegra. Defiende a la mujer porque al juzgarla se le debe al menos un respeto y no se puede negar a nadie el derecho a la felicidad y al amor (El País, 29-IX-1904).

Ya ha prologado otra traducción del italiano Roberto Bracco para la editorial Sempere, hecha por Magdalena S. Fuentes, cuando en 1907, también para la misma editora, traduce En el mundo de las mujeres "Conversaciones feministas" (Bracco: 1907), en la minúscula, como su nombre indica, colección Mignon, con una foto del autor al frente de la obra y dedicatoria autógrafa a la traductora: "A Carmen de Burgos (Colombine) antifeminista, ma... scrittore, Roberto Bracco scrittore, ma feminista."

ARBOR CLXXXVI EXTRA JUNIO 2010 157-168 ISSN: 0210-1963 
La amistad con el autor hizo que éste le rogara prologar a modo de presentación la primera traducción al castellano porque los lectores le conocian como dramaturgo. Carmen advierte de su fama en Italia y de que como prosista es más un pensador al estilo de lbsen o Benavente, por lo que su prosa es sobria y sencilla. En realidad, los cuentos de Muecas humanas resultan muy interesantes por su variedad de argumentos y el estudio del comportamiento humano.

Bracco realiza en En el mundo de las mujeres un ensayo dividido en dos "conversaciones", sobre la evolución de la mujer y sobre la mujer napolitana. Se declara contrario a la inversión de papeles, a que la mujer sea abogado, médico o ministro, aunque no esté tampoco de acuerdo con los que calculan el peso especifico de los cerebros, ni con la lista de Dumas hijo, que clasifica a las mujeres en fuertes, serpientes, guerreras o literatas. Para él la mujer es esencialmente la madre, continuadora de la especie y del mundo.

\section{Colaboración con la editorial Sempere}

Con la editorial valenciana Sempere, que va a publicar la mayoría de las traducciones y versiones hechas por Carmen de Burgos, inicia esta tarea en 1904, pero ya lleva dos años haciendo la labor de correctora de las obras de Blasco. En una carta del director literario a Sempere, tras encargarle que vaya a su despacho de la Malvarrosa y recoja todas las novelas en francés y español, añade:

Además en la biblioteca coja tres o cuatro tomos de novelas antiguas parecidas al folletín de Las Novedades con gravados (sic) y un tomo grande con láminas que se titula La dama del velo blanco.

Junte con esto todas las novelas que yo le envié corregidas(sic) por Colombine, que Ud. guarda en el armario del despacho y envíemelo todo... (Blasco, 1906, 40).

Como editores, la finalidad de Sempere, Llorca e incluso de Blasco, fue siempre obtener la máxima rentabilidad económica, y las relaciones del escritor con sus socios, en torno al dinero, no pudieron ser más tormentosas. Él introduce a Carmen en la editorial y nos interesa cómo explica su método de traducción: que no se precisaba el conocimiento del alemán para traducir a Nietzsche, por ejemplo, puesto que ya lo estaba al francés, y así indica a Sempere: "Coja Ud. los que ya están traducidos al español y sólo hay que dar un repasito al estilo como $\mathrm{Ud}$. veía que hacía yo" (Blasco, 1906: 62).

En otra ocasión insiste a Fernando Llorca, copropietario de la editorial:

"... De una vez para siempre. Traducción exacta, pero en español y con claridad. Trastornar todo lo que sea necesario el original para adaptarlo a la nueva lengua pero sin empequeñecerlo ni desfigurar su sentido.

Hoy le envío una traducción mía del último capítulo del folleto y el original. Fíjese. Así quiero yo la traducción. Esto es fácil" (Blasco, 116).

Esta peculiar "técnica" traductora, sin duda bastante habitual en España, explica el elevado número de títulos que Carmen de Burgos y muchos otros publican de autores ingleses, franceses, rusos o italianos, en ocasiones de manera simultánea.

En 1909 Blasco plantea la necesidad de poner en marcha la colección "novelistas célebres", a peseta el tomo, porque hay un sector del público al que interesa las novela y otro que se nutre con los folletines de los periódicos, "los mamarrachos de Maucci", y un resto de lectores de novelas por entregas. Se vendería un mínimo de "8.000 ejemplares entre España y América" (Blasco, 63).

Antes de que figure como pie de imprenta Sempere, Carmen va a publicar en la Imprenta del Pueblo, propiedad de Blasco Ibáñez, una obra con la que estallará la polémica, y causará el regocijo de los antifeministas y la indignación de las feministas, como sin duda lo era la propia Carmen. Su autor, Paul Julius Moebius, médico psicólogo y filósofo alemán, realiza un estudio psicológico social, antítesis del feminismo contemporáneo, coincidente con Schopenhauer y con Nietzsche y que titula: La inferioridad mental de la mujer.

No merece la pena detenernos en las ideas, por otra parte ya conocidas de este autor que en resumen considera que las doctoras y artistas son producto de una degeneración, que existen instintos comunes entre la bestia y la mujer y que su esterilidad mental es cercana a la imbecilidad, ya que carece de opinión propia y de discernimiento en- 
tre el bien y el mal. Insiste a los médicos en que los ideales feministas son incompatibles con la maternidad, suponiendo que el desarrollo cerebral atrofia los órganos reproductores y queda convertida en un ser andrógino y repulsivo. Concluye que deben demolerse las escuelas superiores femeninas.

Carmen de Burgos acepta sus ideas en contra del feminismo radical, pero pone en duda la tesis de que la mujer sea más imperfecta que el hombre: "La diversa aptitud de los dos sexos no indica inferioridad en ninguno de ellos, sino modalidades diferentes, armónicas y necesarias para la marcha de la humanidad" (10).

El que la mujer quisiera romper estas barreras nítidas entre los dos sexos era considerado como algo negativo, de ahí los múltiples ataques contra el "marimacho".

No creemos, por tanto, que, como afirma Blanca Bravo, la obra de Moebius influyera en la evolución personal de la traductora. Ella misma confiesa su temor inicial por el escándalo de que venía precedido y justifica su trabajo por tratarse de un libro útil "que ataca al feminismo nocivo"; piensa que el feminismo bajo un manto de progreso va contra la libertad humana, y trata de mantenerse en un justo medio con notas aclaratorias, aunque reconoce que hubiera preferido que se titulara, La diversidad de la mujer.

Los tres trabajos suyos que acompañan este texto tratan de dar la réplica a Moebius y, como madre, protesta implícitamente de la incompatibilidad con el hecho de escribir (Bravo, 2003, 76).

Esta obra fue en el extranjero muy discutida y ya en el prólogo de la tercera edición su autor suavizó algo y aclaró, por ejemplo, su opinión sobre que la mujer "debe ser sana y tonta", significaba "no erudita". Si en España fue menos polémica se debió a que la mayoría de las mujeres se ajustaban al ideal de Moebius.

Magdalena Santiago Fuentes, colega de profesión, evitó comprometerse y opinó que el libro estaba cuidadosamente traducido por la "distinguida escritora andaluza, que ha entrado en un periodo de franca actividad de la que pueden esperarse muchos y buenos resultados" (La Lectura, IX-1904, 451-53). No faltó quien se identificó con el men- saje de Moebius, como fue el caso de otra autora, Cándida López Venegas, para quien autor y traductora "se elevaban considerablemente sobre la multitud de presuntuosos y calmaban su alarma inicial ante el título". Reconocía que el alemán escribía tan seco y descarnado, que el lector a veces protestaba por tanta violencia, pero estaba lleno de atinadas observaciones sobre la educación de las jóvenes y la misión difícil de las madres.

"Unas y otras deberian leerlo y no dejarse alucinar por esas teorias feministas que tratan de convertir a la mujer en un ser degenerado, de indumentaria ridicula, de cabellera corta y de lentes ahumados."

Tras felicitar a la traductora, hacía ver la necesidad de libros como éste frente a las mujeres feministas, cuyos modelos eran Jorge Sand o la Nora de Ibsen, "histérica y degenerada", porque "a una parte de nuestros sexos toca sufrir lo que por correr tras un progreso falso, ha cometido la otra mitad:" (La Alhambra 28-II-1905, 86-87).

También Edmundo González Blanco dedicó un largo trabajo a comentar el contenido de esta obra (Nuestro tiempo, 1905$, n. 61,12$)$.

En el año en que inicia su trabajo como traductora con la Viuda de Rodríguez Serra, 1904, también traduce para Sempere las obras de un heterodoxo como Ernesto Renán, el francés autor de La Iglesia cristiana y Los Evangelios y la segunda generación cristiana (Renan, 1904).

El autor, que había sido seminarista y estudiado con el famoso obispo Dupanloup, se dedicó tras su salida a formular su propia teoría sobre el catolicismo. En su introducción justifica la extensión de su obra por la forma en que fue escrita "la leyenda de Jesús" y el misterio que rodeaba la redacción de los Evangelios. Se detiene en el año 160 y el primer volumen lo dedica a la formación de los tres evangelios llamados sinópticos, que constituyen una familia aparte. El cuarto evangelio, atribuido a Juan, quedó en el misterio. El segundo volumen contiene capítulos polémicos y apéndices sobre los hermanos y los primos de Jesús. Acaba con la separación definitiva de la Iglesia y la Sinagoga. Renan evita hacer críticas odiosas de hombres y sistemas que tratan de ignorante y de atrasado: "a quien no admite la última novedad salida de la mente de un joven doctor que lo más servirán de excitación a las investigaciones" (Renan, 1904, 26).

ARBOR CLXXXVI EXTRA JUNIO 2010 157-168 ISSN: 0210-1963

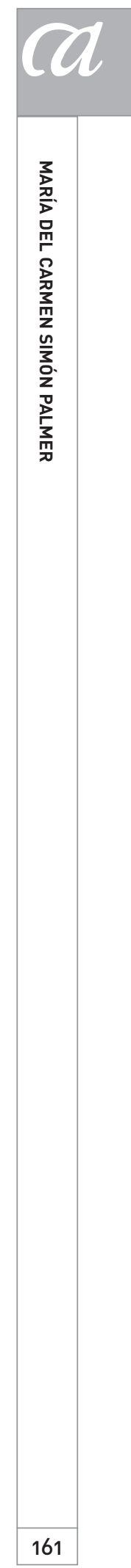


A continuación, Carmen traduce del mismo autor, La Iglesia Cristiana, el último volumen que consagra a los orígenes del cristianismo, al que añade la historia eclesiástica del reinado de Marco Aurelio, cuando el cristianismo cambia de papel y de ser perseguido pasa a protegido y protector del Estado, y el Evangelio "se convierte en una de las bases del absolutismo". El libro comienza con Adriano y acaba con un capítulo dedicado a la fecha del libro de Tobías.

En 1906, y también para Sempere, traduce los dos volúmenes de Leon Deutsch, Diez y seis años en Siberia, una obra prohibida en Rusia, en la que se describe de un modo sencillo las penalidades y las persecuciones de los que son deportados a Siberia (Nuestro tiempo, 1-X-1906, 80 y La Época 19-I-1907, 4).

Creemos que, cronológicamente, lo primero que Carmen de Burgos hace para Prometeo es el prólogo, ya citado, a Muecas humanas, de Bracco, traducida por su colega Magdalena de Santiago Fuentes que llegaría a ser catedrática de Civilización en la Escuela de Estudios Superiores de Magisterio. A continuación, y siguiendo las directrices editoriales de verter al castellano a los autores contemporáneos de éxito, traduce $E l$ rey sin corona de un autor de éxito, pero controvertido, Saint Georges de Bouhélier, con un prólogo firmado en 1908 por Manuel Ugarte, político socialista argentino, que elogia la "hermosa traducción de nuestra admirada Colombine", y escribe unas líneas "por deseo expreso del autor", al que considera el más grande quizá de la nueva generación. En el estreno de esta obra unos años antes, al que asistió el prologuista, en el Theatre des Arts de Paris, a pesar de las polémicas hubo emoción, entusiasmo y triunfo, la aprobaron unánimemente los intelectuales, aunque rompía muchos convencionalismos, y fue comprendida especialmente por el proletariado que Ilenó durante noches el teatro.

El autor, en una Carta a Catulo Mendes sobre el Teatro, el Actor y el Poeta trágico (Saint Georges, 1906: 23551), le confiesa su veneración y trata de su condicion de escritor independiente, sin convencionalismos, por lo que le considera, "un príncipe, un magnifico potentado intelectual que coloca el arte en su verdadero puesto en Francia".

Las reseñas españolas a la obra se hicieron eco de la campaña inútil del llamado gran mundo para hacerle el vacío tras su estreno, por la tendencia del autor marcadamente antiburguesa (Nuestro Tiempo, 1908, n. ${ }^{\circ} 118,162$ ).

Quizás la única crítica velada aparecida de una traducción de Carmen de Burgos fue la hecha de Dafnis y Cloe de Longo, a partir de la versión francesa de Santiago Amyot, obispo de Auxerre. No hemos podido consultar la revista Sagitario en la que el crítico Pérez Bojart, poeta, al hablar de esta traducción indirecta recordaba la directa del griego hecha por Valera (Nuestro Tiempo, 1-X-1906, 262).

Desde los últimos años del siglo XIX y en gran parte gracias a las traducciones al francés, van a multiplicarse las versiones en castellano de la novela rusa sobre la revolución, especialmente dirigidas a los obreros (Gallego, 491). Posterior a 1909 es la que Carmen de Burgos hace de La guerra ruso-japonesa, de León Tolstoi, que recoge una serie de pensamientos y máximas morales escritas entre 1894 y 1898 contra la guerra absurda de Cuba y sobre los pacifistas canadienses, entre otros asuntos (iHombres, despertad!- La guerra hispanoamericana y la guerra de los doukhobors.-Cartago delenda est.- Pensamientos y fragmentos.- Pensamientos inéditos), y que da título al libro, aparecido en 1904 como oposición a la guerra ruso-japonesa y prohibido por la censura.

En el año 1913, Carmen de Burgos acomete una empresa compleja por el volumen de sus Obras, y la profundidad del pensamiento de un autor como John Ruskin, cuyos estudios sociales habian sido traducidos en España por Ciges Aparicio (Cerdá, 1987, 53-68).

Ramón Gómez de la Serna, que ha conocido a Carmen poco antes, accede aunque desconcertado, a su petición de que las prologue:

... En la vida obro por confianza y en usted la tengo sobrada; hemos hablado alguna vez de Ruskin, y coincidimos en las reservas y en las rebeldias que hay que tener frente a su obra.

Nos informa sobre el modo de traducir, que coincide con la idea de Blasco:

... la traducción de Ruskin no es una empresa de estilo, sino de imágenes, de acompañar al autor en las visiones, de reformar la palidez de una traducción literal en la primera 
acepción y una traducción libre en una cualquiera de las otras, de reformarla hasta la precisión debida, y usted puede hacer esto porque ha vivido largas estancias en esa Venecia y en esa Florencia, y sabe la morbidez y la expresión de sus piedras, ese morbo y esa expresión que toman, no en el aislamiento de las fotografías, sino en las obras, en el paisaje, sobre las aguas irrepresentables, elementos con los que tanto contó Ruskin (Ruskin, 1912-13a).

Ramón hace un cuadro descriptivo del autor y un largo estudio que titula "Ruskin el apasionado", donde muestra el paralelismo entre la vida y el estilo del autor, novelesco y exaltado, semejante a una novela de Dickens.

En 1900, José Verdes Montenegro había dedicado un artículo a Ruskin en La Correspondencia de España, con motivo de su fallecimiento en Inglaterra; confiaba en que fuera recordado por lo que de él habían escrito Clarín y Unamuno. Su padre, representante en Inglaterra de los vinos de Jerez, muy interesado por el arte, se hizo acompañar en sus viajes de trabajo por su hijo. Muy joven escribió ya artículos en defensa de Turner y a los veintiséis años su obra Modern Painters. Escritor brillante, ingenioso y de originales teorías estéticas, dio la voz de alarma sobre el peligro que corrían algunas obras de arte, creó varias cátedras de dibujo y tuvo una enorme popularidad entre los estudiantes (La Correspondencia de España, 11-II-1900).

Al aparecer Las piedras de Venecia, el primer volumen (Nuevo Mundo, 17-IV-1913, 10), califica a Colombine de "cultísima escritora", sin hablar de la obra, y Prometeo se admira de lo que considera "un alarde, admirable, gallardo, grande y diáfano con que inicia esta mujer fuerte y decisiva la divulgación de las obras completas de Ruskin", y aclara que, en el prólogo, Gómez de la Serna trata de encontrar el valor en que descansó la mística "de aquel santo varón contemplativo" (Prometeo, 1-III-1912, 56). También EI motín se felicita por la labor "concienzuda de la cultísima escritora" (El motín, 20-III-1913).

Aquel mismo año de 1913 aparece el resto de las obras de Ruskin, que muestran su clasicismo y su amor por el arte: Las mañanas de Florencia (Ruskin, 1913b), El reposo de San Marcos: historia de Venecia para los raros viajeros que se ocupan todavía (Ruskin, 1913c), un estudio de la historia de esta ciudad, a través de los fragmentos de manuscritos "ennegrecidos" que se salvaron en la Biblioteca Nacional;
Las siete lámparas de la Arquitectura (Ruskin, 1913?d); Los pintores modernos (Ruskin, 1913e), donde trata del papel de la pintura, el paisaje moderno, los maestros de Turner y la pintura turneriana, todo con un estilo claro y un tono pedagógico.

Sobre temas de actualidad versan la serie de sus conferencias reunidas bajo el título general de La corona de olivo silvestre. (Ruskin, 1913) de las que nos interesa especialmente la titulada Los lirios de los jardines de las reinas, una defensa de las ventajas de la instrucción y del libro porque permite consultar a los sabios como Shakespeare, Dante u Homero. Ahora bien, atribuye a la mujer el papel de entera sumisión y guía y al hombre el de acción, creación y protección:

La inteligencia de ella no es de inventiva ni creadora, sino toda entera de amante influencia, de arreglo, de orden, de decisión. Su gran arma es la dulzura. Por su misión y su sitio en el hogar está preservada de muchas tentaciones y peligros (Ruskin, 1913, 153g).

Aconseja la sabiduria en la mujer para no elevarse sobre su marido, dulzura apasionada y una modestia infinita. Naturalmente en su educación son precisos los "ejercicios físicos que afirmen su salud y perfeccionen su hermosura", para así "adecentar su poder". Hay que modelar en primer término su envoltura física y en seguida, llenar y enriquecer su espíritu con todas las ideas que puedan afirmar su instinto de justicia y su sentido innato del amor. Es inútil que sepa varias lenguas y tampoco importa ni interesa que esté versada en alguna ciencia, especialmente en la Teología, porque el objeto de la educación no es convertirla en un diccionario, aunque concede que "es absolutamente preciso que se le enseñe a penetrar en la historia que lee". Aconseja que aprenda nociones generales de uso cotidiano y práctico y la literatura únicamente "para inculcarla paciencia y seriedad, de manera que debe evitarse la tentación enfermiza hacia la lectura de novelas y revistas, y su lectura siempre será guiada" (Ruskin, 1913, 176g).

Cuando, ya en 1920, Carmen traduce la obra de Marcela Tinayre, La dulzura del vivir, dentro de la colección "La novela literaria", con un prólogo de Blasco Ibáñez, en que hace un estudio biográfico y crítico de la obra, la propia Carmen se autorreseña con su seudónimo de "Perico el

ARBOR CLXXXVI EXTRA JUNIO 2010 157-168 ISSN: 0210-1963 
de los Palotes", usado en El Heraldo y considera a Tynaire una de las mejores novelistas francesas, y su obra, el mejor alegato en favor de la mujer, aunque no pasan cosas extraordinarias, ni hay argumento, pero al estar llena de poesía y de interés se llega de un tirón a la última página. Es una muestra de la impresión que la luz de Nápoles causa en las mujeres del Norte, sus costumbres, y la diferencia de los caracteres latinos. Y respecto a su labor dice:

Se nota que la traductora ha llevado con apasionamiento su versión al castellano por la delicadeza del alma de mujer y gozar de las magnificas reflexiones, tan exactas de Nápoles y Pompeya ("Perico el de los Palotes", El Heraldo de Madrid, 15-VII-1920).

La editorial Sempere pasó a ser Editorial Prometeo hacia 1914 y propiedad de Vicente Blasco Ibáñez, que prologa las traducciones publicadas alli desde ese momento.

\section{Traducciones en la editorial Maucci}

El fundador de la editorial, Emanuele Maucci (Parana, Italia 1850) emigró a Argentina junto con varios hermanos y primos y prosperó como vendedor de libros, para marchar luego a México como editor y librero. Se estableció en Barcelona en 1892 desde donde consiguió una difusión internacional gracias a la exportación de libros a América y un enorme éxito popular. Le interesaron fundamentalmente las ediciones baratas, con traducciones mediocres en muchos casos y portadas vulgares, pero con las que acaparó el antiguo mercado de libros por entregas, ejemplares de leer y tirar, y de los que vendía al año un millón de ejemplares sólo de libros de una peseta entre España, América y Filipinas. En Francia, la editorial Hachette "hacía libros con el mismo precio y mejor calidad, pero Maucci era de un mercantilismo insaciable" (Lamas, 2002, 11-13).

... por regla general lo que cobra un traductor por 300 planas, son de trece a catorce duros; muy escasos los que llegan a quince y rarisimos los que cobran, con mucho trabajo lo que haria pagar un copista por copiarlo. ¿Qué quieren que haga el infeliz que se ve condenado a este trabajo de presidiario, para ganarse la vida? Salirse lo antes que pueda, para que le quede un jornal arreglado (Pous, 1902, 118-120).
Para Maucci, Carmen hace una versión a partir de la $5 .^{a}$ edición italiana de la obra del médico y antropólogo italiano Pablo Mantegazza, Fisiologia del placer, escrita en 1854, a los veintidós años y sin haber leído ningún libro sobre la materia, según confesión propia, y con ligeras modificaciones en las numerosas reediciones. El autor divide la materia entre los placeres de los sentidos y los placeres del sentimiento.

En la Biblioteca "Arte y Literatura" figuran Clarín, Andrenio y Colombine, y esta última traduce en la colección "Viajes y Aventuras" a un autor con verdadero éxito de ventas, Emilio Salgari, en este caso, La conquista de un imperio, ilustrada por A. Della Valle. En la revista Prometeo se recomienda la traducción "hecha a conciencia por la admirable escritora CB", compañera de redacción y "cuyo espiritu fantasioso y pintoresco ha hecho esto tan bien que se ha contado a sí misma, en ratos de descanso, estas aventuras maravillosas" (Prometeo, 1-VIII-1911, 64). A ese primer título siguieron, en el mismo año de 1911, Los misterios de la India y Los últimos filibusteros, todas ellas ilustradas por el mismo dibujante.

\section{Editorial Araluce}

Ramón Arauce, editor catalán, sería especialmente conocido por sus libros para jóvenes, adaptación en muchas ocasiones de clásicos.

Una de las tareas emprendidas por Carmen fue la recuperación de la cultura sefardita, de acuerdo con el doctor Ángel Pulido e intelectuales del momento de distintas ideologías como Galdós, Menéndez Pelayo, Pardo Bazán, etc., y en la Revista Crítica, el primer periódico que en España abrió una sección dedicada al pueblo israelita, escribe una sección llamada "Letras sefarditas". En octubre de 1905 se había entrevistado con Max Nordau, seudónimo de Max Simon Suedfeld, a quien consideraba un gran pensador y que no se mostraba muy optimista en cuanto a la recuperación de esta cultura. Efectivamente, Revista Crítica, dirigida por Carmen, duró poco, de modo que trasladó su sección a Prometeo, dirigida por Ramón. En 1910, un año después, crearía la Alianza Hispano-Israelí.

En el año 1914 llega a España el autor húngaro, acompañado de su mujer y su hija Maxa, y hace amistad con 
el autor judio Cansinos- Assens, que había traducido su novela Matrimonio morganático.

Los Cuentos a Maxa (La muñeca soberbia, la vida y la muerte.- El hermano travieso y la hermana juiciosa.- El Maestro), encajan perfectamente con la línea editorial de Araluce por su brevedad, diez páginas aproximadamente cada uno, escritos por un padre a su hija "con la profundidad acostumbrados (Heraldo de Madrid, 20-VI-1914). No se menciona en la reseña a la traductora, pero se elogian las caracteristicas formales de la edición: láminas, papel y formato, típico alemán. Esta niña, Maxa, será ya en 1918 una famosa dibujante, ilustradora de libros a la que la propia Carmen, años más tarde (La Esfera, 17-IX-1927) en "Una misionera sefardita", elogia y comenta que durante su estancia en España había sido alumna de Mezquita. En Esfera, 28-IX-1929), habla de la tumba en Tel-Aviv de Max Nordau, "el filósofo romántico lleno de ternura y bondad", y considera a su hija una princesa israelita, pintora de retratos famosa.

Nordau había tenido no muy gratas experiencias, antes de su visita a España, con el editor Sempere, al que exigió derechos de autor. Blasco Ibáñez escribía así a Sempere en 1905:

$Y$ ahora un asunto grave. Acabo de recibir la adjunta carta de Max Nordau. Es un señor de muy mal genio, y, como Ud. verá, la carta no puede ser más agria y de peor tono para mí, pues me supone así como un estafador. Yo creía que la cuenta estaba saldada hace tiempo.

Este es un asunto de horror y no puedo tolerar el permanecer más tiempo en ridículo.

Es preciso enviarle enseguida el dinero que sea, pero enseguida y que Ud. me lo diga a mí para escribirle como merece (Blasco, 1905, 49).

\section{Otras editoriales. Otros autores}

Hemos visto cómo varios editores inauguran colecciones destinadas a divulgar en España la literatura europea; así, Ruiz-Castillo Franco en 1910 con su "Biblioteca Nueva", de sentimientos en que es maestro este famoso escritor" y que se diferencian de los "sosos y relamidos" a que están 1929, en un artículo titulado "La tierra reconquistada" ( $L a$ para la que traducen importantes escritores del momento como Enrique Díez-Canedo, Julio Gómez de la Serna, Alfonso Hernández Catá, Benjamín Jarnés, Cipriano Rivas Cherif, Rafael Cansinos Assens, etc., textos de Pirandello, Papini, Apollinaire, D'Annunzio, G. de Nerval, etc. Ramón Gómez de la Serna tenía la última palabra en la elección de autores como director, y se encargaba de realizar gran parte de los prólogos que precedían a las traducciones, que luego reunió en su volumen Efigies (Gallego, 2004, 479-500).

Carmen de Burgos traduce para la Biblioteca Nueva, Las hijas del fuego de Gerard de Nerval, seudónimo del escritor Gerard Labrunie, romántico, traductor de Goethe y Schiller, colaborador de Dumas, amigo de Gautier y Victor Hugo. Enamorado de Oriente y de varias mujeres exóticas, formó parte de la bohemia parisiense y el desenlace de sus trastornos mentales fue su suicidio en una farola de Paris, suceso litografiado por Gustave Doré.

Como era habitual en las traducciones de la "Biblioteca Nueva", escribe el prólogo su director, Gómez de la Serna, titulado: "El suicida G. de Nerval", donde hace su biografía, destaca su condición de políglota y afirma que el autor sentía como algo ilegítimo el no ser hijo de los nobles propietarios del caserío donde nació (Nerval, 5-80). El libro incluye las narraciones: Silvia-Jemmy-Octavia-Isis y Corille

En Ediciones Españolas, Carmen traduce La perseverancia, de H. Besser, sobre los peligros de la indecisión y la facilidad de entusiasmarse, acompañados de ejercicios prácticos para adquirir la perseverancia, muy curiosos, como contar, mover las manos, hacer cosas con hilos, etc. Incluye una leyenda noruega que relata el viaje de un joven desde su pueblo al de su prometida para casarse con ella, y se olvida, como ejemplo de la falta de perseverancia.

Algo inhabitual, por tratarse de una escritora clásica, es su traducción de La princesa de Clèves, escrita por Madame de La Fayette, primera novela histórica femenina francesa, sin anotaciones y que, muy posiblemente, sería un buen éxito de ventas. Ha sido reeditada recientemente por RBA.

Sin pie de imprenta aparece su traducción de una obra de carácter práctico de Rose Nicolle, Una idea de parisiense por página, subtitulada en la cubierta: "500 consejos, ideas y recetas de belleza y elegancia", con afirmaciones del tipo

ARBOR CLXXXVI EXTRA JUNIO 2010 157-168 ISSN: 0210-1963

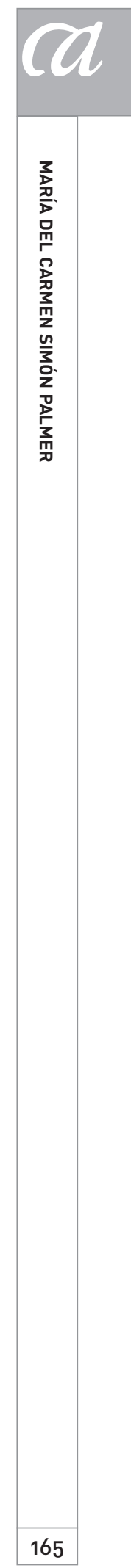


de: "ser fea, a menos que seas una elevada filósofa, es tener una vida obscura, inútil y triste".

Creemos que su última traducción, para la Editorial Rivadeneyra, y también la más atrevida, incluso en nuestros dias cuando ha sido reeditada por "La sonrisa vertical", fue El ratoncito japonés (La souris japonaise) de la novelista francesa Rachilde, seudónimo de Marguerite ValletteEymery. La autora había sido definida en su juventud como "Madame Perversidad" por Rubén Darío en su libro Los Raros, y siempre fue ajena a todo tipo de convencionalismos, como declaraba ya en 1923 y siendo esposa del director del Mercure de France, al escritor y diplomático peruano García Calderón (García, 1989, 44-46).

El libro, las confesiones de sus aventuras amorosas por un Don Juan a su abogado, fue considerado "escabroso" y "peligroso", pero de intención y hechura perfectamente nobles como arte. Escandalizó en Francia "a los de siempre" pero no se le ocurrió al prefecto de policía retirarlo de las librerías, porque "alli no se condena al escritor que escribe sobre el asunto que le da la gana, ni se confunde con aquel que hace "cosas pornográficas por encargo del editor. El talento es libre, desde Madame Bovary y Las flores del Mal, y no se condena en literatura más que la sosería, la cursilería y la mentecatez".

La propia autora en el Mercure de France, donde hacía la crítica de novelas, escribió sobre su independencia.

No creo en una moral bajada del cielo o que remonta a él. Creo que hay tantas morales como individuos. Para uso personal de mi cerebro no existe sino lo que es feo y lo que es hermoso. Es preciso no hacer nada sucio, ni nada feo. Por lo demás, toda literatura es lícita (Mercure de France, 15-III-1921).

Alberto Insúa, en su prólogo, concede que la obra es amoral, si se quiere, pero literatura y considera a Rachilde la cultivadora más eminente del satanismo porque todos sus personajes tienen dentro algún demonio, ya sea la lujuria, el hastío, etc. Ante los que mantienen que la literatura satánica ya no gusta, defiende que se necesita un Mirbeau, un Jean Lorrain o una Rachilde.

No es una novela blanca para señorita quinceabrileñas, ni una novela verde, para ancianos del mismo color. Es una novela roja, color de fuego y de sangre. Turbia y espantosa por momentos, como ávida cuando se la bebe hasta el fondo y sin pavor, haciendo uso del microscopio y del bisturí.

\section{Conclusiones}

Resulta innecesario resaltar el ingente trabajo realizado por Carmen de Burgos para facilitar la tarea de modernización de nuestra literatura con el conocimiento de los movimientos literarios europeos.

La generosidad, evidente a lo largo de su vida, queda patente incluso en algo tan inhabitual como el agradecimiento a unos editores que nunca se destacaron por su esplendidez.

Su valor al traducir alguna obra prohibida por diferentes motivos fuera de España le costó algún que otro enfrentamiento, como hemos visto, con compañeros que alardeaban de ideas liberales. Tan sólo podría objetársele, precisamente por su ideología feminista, el que vertiera al castellano obras claramente ofensivas para el desarrollo intelectual de la mujer, algo que ella trató de justificar con otros escritos en los que procuraba situarse en una postura intermedia. La aparente contradicción podría explicarse de muchas maneras que irian desde la necesidad económica hasta la presión de unos editores que veían en estos textos un elevado número potencial de lectores, precisamente por ser ella la traductora. 
1 "Este ensayo se ha realizado en el marco del proyecto de investigación (FFI2009-11455. Ministerio de Ciencia e Innovación)".

\section{Traducciones de Carmen de Burgos}

Besser, H.: La perseverancia, traducción de Carmen de Burgos, Madrid, Ediciones Españolas [s.a. 1919?] 123 pp.

Boex, Joseph Henri Honoré: La indomada, novela, prólogo de Vicente Blasco Ibáñez, Valencia, Editorial Prometeo, [s.a], 327 p. (La novela literaria).

Blanchard, B.: Lo que debe saber toda recién casada, Madrid, Ediciones Españolas, 1917, 125 pp.

Bracco, Roberto: En el mundo de las mujeres (Conversaciones feministas), traducción de Carmen de Burgos (Colombine), dibujos de L. A. Brime, Madrid, Viuda de Rodríguez Serra, 1906, 90 pp. (Biblioteca Mignon; 50).

- Muecas humanas, traducción de S. Fuentes, prólogo de Carmen de Burgos Segui, Valencia, F. Sempere y Cía. [s.a] 233 pp.

Deutsch, León: Diez y seis años en Siberia, Valencia, Editorial Sempere [s.a. 1906] $2 \mathrm{v}$.

Fava, Honorato: Renunciación. Novelas, traducción del italiano por Ricardo Franco, prólogo de Carmen de Burgos, Valencia, F. Sempere y Compañia, Editores [s.a. 1911?], 222 pp.

Keller, Hellen: Historia de mi vida. Sorda, Muda, Ciega, prólogo del Excmo. e IImo. Sr. D. Eloy Bejarano y Sánchez inspector general de Sanidad interior, vocal de los Reales consejos de Sanidad e Instrucción Pública, Comisario regio de Colegio de Sordomudos

Recibido: 14 de mayo de 2010 Aceptado: 7 de junio de 2010
Burgos (Colombine) profesora por oposición de la Escuela Normal y de Sordomudos y Ciegos, Madrid, Viuda de Serra, editor [1904] XIV, 262 pp.

La Fayette, Marie Magdeleine Picoche de la Vergne, comtesse de: La princesa de Clèves, traducción de Carmen de Burgos, Barcelona, Cervantes [s.a. 1919], $221 \mathrm{pp}$.

Longo: Dafnis y Cloe. (De la versión francesa de Santiago Amyot, obispo de Auxerre), traducción de Carmen de Burgos, Valencia, Sempere y Compañía editores [s.a.], 288 pp. (Los clásicos del amor).

Mantegazza, Paolo (1831-1910): Fisiología del placer, versión española de Carmen de Burgos, Barcelona, Maucci [s.a. 1913?] $2 \mathrm{v}$.

Mattachich, Gera: Loca por razón de Estado. La princesa Luisa de Bélgica. Memorias inéditas del Conde [Gera] Mattachich, traducción y prólogo de Carmen de Burgos, obra prohibida y secuestrada en Austria, Madrid, Viuda de Rodríguez Serra, 1904, XXII, 168 pp.

Moebius, Paul Julius: La inferioridad mental de la mujer, versión española y prólogo de Carmen de Burgos, Valencia [Imp. del Pueblo] [s.a. 1905], 239 pp.

Nerval, Gerard de (seud.) (Gerard Labrunie) (1808-1855): Las hijas del fuego [Prólogo de Ramón Gómez de la Serna], traducción de Carmen de Burgos, Valencia, Biblioteca Nueva [s.a], 269 pp.

Nicolle, Rose: La decisión, traducción de Carmen de Burgos (Colombine) [s.p.i. 1917?], 118 pp., 2 hs.

- Una idea de parisiense por página [Consejos, ideas y recetas de belleza $u$ elegancia], traducción de Carmen de Burgos (Colombine), Madrid [Juan Pueyo. 1917?], 238 pp.

Nordau, Max [seud.] Max Simón Suedfeld (1849-1923): Cuentos a Maxa, versión 
castellana de Carmen de Burgos, ilustraciones de R. Lorenzale, Barcelona, Editorial Araluce [1914], 232 pp., 9 láms.

Renan, Ernest: La Iglesia cristiana, traducción de Carmen de Burgos Seguí, Valencia, F. Sempere [s.a. 1905?], 280 pp.

- Los Evangelios y la segunda generación cristiana, traducción de Carmen de Burgos Seguí, Valencia, F. Sempere

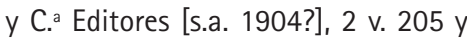
$214 \mathrm{pp}$.

Rachilde: El ratoncito japonés de Marguerite Vallette-Eymery (1860-1953), traducción de Carmen de Burgos, Madrid, Libreria Editorial Rivadeneyra [s.a. 1923], 255 pp. (escritores contemporáneos).

Ruskin, John (1819-1900a): Las piedras de Venecia. Prefacio de Ramón Gómez de la Serna, traducción de Carmen de Burgos, Valencia, F. Sempere y Cía. [1912-1913] $2 \mathrm{v}$.

- (1819-1900b): Las siete lámparas de la arquitectura: el sacrificio, la verdad, la fuerza, la belleza, la vida, el recuerdo, la obediencia, traducción de Carmen de Burgos, Valencia, F. Sempere [s.a. 1910?], 257 pp.

- (1819-1900c): Las mañanas de Florencia (estudios sencillos de arte cristiano), traducción de Carmen de Burgos, Valencia, F. Sempere y Cía. [1913?], 212 pp.

- $\quad$ (1819-1900d): Los pintores modernos. El paisaje, traducción de Carmen de Burgos, Valencia, F. Sempere y Cía. [1913], 227 pp.

- (1819-1900e): El reposo de San Marcos: historia de Venecia para los raros viajeros que se ocupan todavía de sus monumentos, traducción de Carmen de Burgos, Valencia, Prometeo Soc. Edit. [1915], VIII, 274 pp.
- $\quad$ (1819-1900f): La Biblia de Amiens, traducción de Carmen de Burgos, Valencia, Prometeo [s.a. 1916], XII, 233 pp.

- (1819-1900g): La corona de olivo silvestre; El trabajo; El tráfico; La guerra; Losjardines de las reinas, traducción de Carmen de Burgos, Valencia, F. Sempere y Compañía [1913?], 188 pp.

Saint-Georges de Bouhélier (1876-1947): El rey sin corona: drama en cinco actos, seguido de una carta a Catulo Mendes sobre el Teatro, actor el teatro y el poeta trágico, prólogo de Manuel Ugarte, traducción de Carmen de Burgos, Valencia, F. Sempere y Compañia [s.a. 1908], XIII, 254 pp.

Salgari, Emilio (1862-1911): La conquista de un imperio, versión española de Carmen de Burgos, obra ilustrada con 20 grabados de A. Della Valle, Barcelona, Maucci [1911], 414 pp. (Viajes y aventuras).

- Los misterios de la India, versión española de Carmen de Burgos, Barcelona, Maucci, 1911, 382 pp.

- Los últimos filibusteros, versión española de Carmen de Burgos, obra ilustrada con 20 grabados de A. Della Valle, Barcelona, Maucci [1911?], 350 pp. il. (Viajes y aventuras).

Tinayre, Marcela (1872-1948): La dulzura de vivir, prólogo de Vicente Blasco Ibáñez, versión de Carmen de Burgos, Valencia, Ed. Prometeo [s.a. 1920], 305 pp. (La novela literaria).

Tolstoi, Leon (1828-1910): La guerra rusojaponesa, traducida por Carmen de Burgos, Valencia, F. Sempere y Compañia, Editores [s.a. posterior a 1909], $202 \mathrm{pp}$.

Vallete-Eymery, Marguerite (Rachilde): El ratoncito japonés, prólogo de Alberto Insua, Madrid, Editorial Rivadeneyra, 1923, 255 pp.

\section{BIBLIOGRAFÍA}

Botrel, Jean-François (1987): "La obra española de Paul Feval", en Paul Feval, 1816-1881, Rennes, Bibliotheque Municipale.

Bravo Cela, Blanca (2003): Carmen de Burgos (Colombine) contra el silencio, Madrid, Espasa.

Cerdá i Surroca, María Ángela (1987): "Influencias inglesas en la génesis del Modernismo: Ruskin y Morris", en El Modernismo Español e Hispanoamericano, Córdoba, Diputación de Córdoba.

Gallego Roca, Miguel (2004): "De las vanguardias a la Guerra Civil", en Historia de la Traducción en España, Francisco Lafarga \&t Luis Pegenaute (eds.), Salamanca, Editorial de Ambos Mundos.

García Calderón, Ventura (1989): "En casa de Rachilde", en Obra literaria selecta, prólogo Luis Alberto Sánchez, Lima, Biblioteca Ayacucho.

Lamas, Manuel (2002): "Notes sobre l'editorial Maucci y les seves traduccions", Quaderns: revista de traducción, 8.

Núñez Rey, Concepción (2005): Carmen de Burgos "Colombine" en la Edad de Plata de la literatura española, Sevilla, Fundación José Manuel Lara.

Piula, Joseph [Josep Pous i Pagés] (1902): "El moviment editorial a Barcelona", Catalunya Artística, 27 febrero.

Robles, Laureano (2005): "Krautsky, Unamuno y La cuestión agraria (Un texto poco conocido)", Cuadernos de la Cátedra Miguel de Unamuno, 40.

Simón Palmer, María del Carmen (1991): "Carmen de Burgos [biobibliografia]", en Escritoras españolas del siglo XIX. Manual bio bibliográfico, Madrid, Castalia. 